\title{
The effect of freedom of choice in increasing vegetable consumption in Greek pre-school children: The HabEat Study
}

\author{
V. Costarelli ${ }^{1}$, G. Moschonis ${ }^{2}$, A. Yiannopoulou ${ }^{2}$ and Y. Manios ${ }^{2}$ \\ ${ }^{1}$ Human Ecology Laboratory, Department of Home Economics and Ecology, Harokopio University and \\ ${ }^{2}$ Department of Nutrition \& Dietetics Harokopio University, 70 El. Venizelou Ave, 17671 Kallithea, Athens, Greece
}

Consumption and liking of vegetables in preschool children is low and strategies to improve intake in this age group are of great importance. Choice-offering, as a possible strategy to increase intake of vegetables in pre-school children, has not been thoroughly investigated in the past ${ }^{(1-3)}$. The aim of this study was to explore the possible effect of free choice in increasing the consumption vegetables in pre-schoolers.

Fifty-two children (two classes), 3-5 years old (mean $=4.10$ years, $\mathrm{SD}=0.37$, boys $67.3 \%$ ) participated in this, with-in subject design, study. Three different vegetables that were familiar to children and were of equal liking, were selected for the study, after a pre-test (carrot, cucumber and tomato). The children were offered the vegetables (100gr portion) in the nursery, in a raw form, as a starter, prior to the main meal of the day, under two different experimental conditions: freedom of choice and no choice. The duration of the study was 3.5 weeks (twice a week). The results are presented in the following table:

Table: Consumption of the vegetable/vegetables (total) in the 6 visits of the intervention (grams)

\begin{tabular}{lllr}
\hline & & & Vegetable/s consumed (gr) \\
\cline { 2 - 4 } Nursery Visits & Conditions & Mean & SD \\
\hline Visit 1: Stimulus C class1 \& A class 2 & No choice & 50 & $43 \cdot 10$ \\
Visit 2: Stimulus A class1 \& B class 2 & No choice & 37 & $56 \cdot 16$ \\
Visit 3: Stimulus B class1 \& C class 2 & No choice & 40 & $27 \cdot 75$ \\
Visit 4: mixed stimulus A B \& C & No choice & 40 & $42 \cdot 58$ \\
Visit 5: Stimuli A, B or C & Free choice & 46 & $57 \cdot 26$ \\
Visit 6: Mixed alternatives AB, AC or BC & Free choice & 43 & $37 \cdot 20$ \\
\hline
\end{tabular}

Vegetable stimulus A (cucumber), B (tomato) \& C (carrot)

The freedom of choice condition seems to lead to an increased consumption of the vegetables in comparison to the no choice condition ( $p=0.002$ Friedman test). To investigate the effect of freedom of choice on vegetable consumption (across stimuli) the Wilcoxon pair test has been employed. There were statistically significant differences in vegetable consumption between visit 1 (no choice) with visit 5 (freedom of choice), $p=0.031$ and between visit 3 (no choice) and visit 5 (freedom of choice), $p=0.0001$. In addition, when comparing visit 4 (mixed stimulus-no choice) with visit 6 (combination of 2 vegetables- freedom of choice) the children consumed significantly more vegetables in condition $6, \mathrm{p}=0.008$.

It is plausible, that offering a choice of vegetables to toddlers, may be a useful strategy to increase vegetable consumption.

1. Russell CG \& Worsley A (2007) Public Health Nutrition 10, 1223-33.

2. Zeinstra GG, Renes RJ, Koelen MA et al. (2010) American Journal of Clinical Nutrition 91, 349-56.

3. Domínguez PR, Gámiz F, Nájera MG et al. (2013) Food Quality and Preference 30, 108-113. 